\title{
Transcriptional basis of the acclimation to high environmental temperature at the olfactory receptor organs of Drosophila melanogaster
}

\author{
Jacob Riveron ${ }^{1,2}$, Tamara Boto ${ }^{1,3}$ and Esther Alcorta ${ }^{1 *}$
}

\begin{abstract}
Background: Environmental temperature directly affects the concentrations of chemicals in the gas phase. Therefore, if the olfactory system does not physiologically adapt to environmental conditions, it may provide inadequate information about the distance to or direction of odor sources. Previous reports have shown at the behavioral level that temperature induces changes in olfactory sensitivity in Drosophila melanogaster. These changes are initiated in the main olfactory receptor organs, the antennae. In this work, we attempted to identify the particular genes responsible for olfactory adaptation to increasing temperatures in these organs based on current knowledge of the molecular basis of olfactory reception.

Results: Whole-genome transcriptional responses to transitory temperature shifts from $21-30^{\circ} \mathrm{C}$ were analyzed in the third antennal segments of Drosophila. More than $53 \%$ of the genome was expressed in these organs; this percentage increased slightly (55\%) after heat treatment. However, the expression levels increased for $26 \%$, decreased for $21 \%$ and remained constant for 53\% of the expressed genes. Analysis of the changes produced in 389 genes related to heat response and olfactory reception, according to the current functional annotations of the Drosophila gene set, showed significant differences in 95 of these genes, which are involved in the heat response (23), perireceptor events in olfaction (50), olfactory and gustatory receptors (18) and G-proteins and transduction cascades (4).

Conclusions: Gene expression was altered in response to environmental heat in the antennae of Drosophila by increasing or decreasing expression. Different acclimation patterns emerged for reception through the basiconic, trichoid and coeloconic sensilla. Changes in genes with a central role in olfactory reception, such as orco, may account for part of the acclimation reported at the behavioral level.
\end{abstract}

Keywords: Olfaction, Olfactory acclimation, Olfactory reception, Environmental temperature, Drosophila melanogaster, Microarray analysis, Olfactory reception genes

\section{Background}

Organisms live in a dynamic environment in which climatic factors change continuously, not only between different seasons but also during the same day or in the different microhabitats in a small area. In this continuously changing environment, sensory systems in general and the olfactory system in particular must be able to adjust to provide accurate information to organisms [1].

The environmental temperature affects the concentrations of chemicals in the gas phase. Thus, rising

\footnotetext{
*Correspondence: ealcorta@uniovi.es

'Department of Functional Biology, Faculty of Medicine, University of Oviedo, Oviedo 33006, Spain

Full list of author information is available at the end of the article
}

temperatures increase the volatility and concentrations of odorants in the air. Several reports have addressed the ability of the olfactory system to adapt to high odorant concentrations in the environment [1]. In Drosophila, central $[2,3]$ and peripheral elements of the olfactory system are responsible for such adaptation $[4,5]$.

Furthermore, it has been shown through behavioral tests that temperature influences olfactory sensitivity in Drosophila melanogaster [6]. The biological effects of olfactory adaptation to temperatures fluctuating within the normal range, from 15 to $30^{\circ} \mathrm{C}$, have been reported. At intermediate odorant concentrations, the environmental temperature and olfactory sensitivity appear to be negatively correlated. These results support the notion that 
adaptation of the olfactory system provides accurate information to the animal, compensating for modifications of chemical volatility. Further studies involving the main olfactory receptor organs, the antennae, have shown that changes in olfactory responses begin during the reception process and appear at the neuron receptor level [7].

The same pattern of responses has been observed whether the temperature shift lasts a few hours or several days. Therefore, searching for gene expression changes, which are most likely necessary for long-lasting responses, may help to shed light on the basis of olfactory adaptation to heat at the reception level. To elucidate the molecular mechanisms involved in this process, we performed an analysis of differential gene expression in the antennae using microarrays.

Whole-genome gene expression arrays have been used previously in Drosophila to identify genes that are responsible for adaptation to high and low temperatures. For example, gene expression patterns have been analyzed in the following contexts: a) selection experiments for heat and cold resistance [8,9]; b) Drosophila lines subjected to different heat treatments [10]; and c) natural populations corresponding to different geographical locations [11]. However, in these studies, emphasis was placed on global issues concerning the effect of heat stress on the whole organism and not on the particular response of the olfactory system.

Some attention has also been paid to the changes in the transcriptional profiles of olfactory genes under different biological conditions [12] and in response to special treatments. Due to the social impact of alcoholism, several microarray studies have focused on understanding the molecular changes that occur after exposure to ethanol using various model organisms [13]. Thus, it is known that in D. melanogaster, exposure to ethanol causes a decrease in the expression of genes affecting olfaction, among other changes [14-17].

Other studies related to olfactory gene expression have focused on insect vectors of human diseases, such as the malaria mosquito, Anopheles gambiae [18-21]. Thus, the differential expression of odorant-binding-protein genes (OBPs) has been found to be related to the eating behavior of male and female mosquitoes, depending on their metabolic status [22,23].

In this report, we concentrate on the genome expression changes that appear in the main olfactory receptor organs of Drosophila after exposure to high temperatures. With this aim, wild-type Canton-S flies were subjected to 48 -hour treatments at $30^{\circ} \mathrm{C}$. First, we provide a general overview of the genes whose expression is most altered due to heat, based on the Gene Ontology (GO) functional groups defined in Drosophila. Then, to examine the processes related to the olfactory function in greater detail, we used a direct approach, selecting specific tissues and conducting a priori selection of the genes to be examined via microarray analysis using literature-based functional information. Differential gene expression analyses of the third antennal segments were performed to compare control and treated flies.

Special attention was paid to those genes related to olfactory reception and heat response, which were represented by 389 probesets. These genes may play an important role in the olfactory adaptation of insects to heat, which has been demonstrated functionally at the whole-individual level [6] and in the olfactory receptor organs [7].

Finally, we tested the contribution to the adaptation to heat of the orco gene, which is a gene related to olfactory reception that is expressed in more than $70 \%$ of olfactory receptor neurons [24]. With this goal, we simulated the expression changes in this gene due to heat via genetic manipulation and studied the functional consequences in response to odor.

\section{Results and discussion RT-PCR validation}

The microarray results were validated via real time-PCR for 9 genes, representing approximately $10 \%$ of the genes selected based on their potential interest from the larger pool of genes demonstrating significant changes in expression in the microarray analysis (95/389). Btubulin60D was used as an internal control. An equal efficiency for every pair of primers compared to the controls was confirmed, and the fold-change levels were determined. The results were consistent with the microarray analysis data with respect to the direction and amount of change, 5 of which were upregulated, while 4 were down-regulated (Table 1 ). Regression analysis of the qPCR fold-change levels compared to the correspondent microarray results for the 9 genes yielded the following regression line $y=0.775 x+0.206$ with a highly significant correlation value of $\mathrm{r}^{2}=0.999$ (Ftest $=$ 6641.86, $\mathrm{P}<0.0001)$.

Table 1 Expression changes due to the heat treatment measured using microarrays or RT-PCR

\begin{tabular}{lcc}
\hline Gene & $\begin{array}{c}\text { Fold change } \\
\text { (Microarrays) }\end{array}$ & $\begin{array}{c}\text { Fold change } \\
\text { (RT-PCR) }\end{array}$ \\
\hline or47b & 1.66 & 1.33 \\
\hline gr21a & 1.67 & 2.09 \\
\hline hsp67Bb & 32.54 & 25.43 \\
\hline per & 0.51 & 0.71 \\
\hline hsc70Cb & 1.92 & 1.31 \\
\hline ir21a & 1.42 & 1.30 \\
\hline ugt86Da & 0.76 & 0.81 \\
\hline pbrp4 & 0.71 & 0.61 \\
\hline obp49a & 0.68 & 0.72 \\
\hline
\end{tabular}




\section{Microarray analysis}

A total of 8 microarrays were analyzed, 4 for each group of control or heat-treated flies. Pools of approximately 4,000 antennae per array were used (see Methods). Prior to the gene expression analysis, the samples were paired in a dendrogram based on a comparison of the expression profiles of all the genes (Figure 1A). The antennae samples collected from heat-treated flies formed a separate and distant cluster from the control samples, which aggregated in a second cluster. This observation reflects the effectiveness of the treatment and the importance of

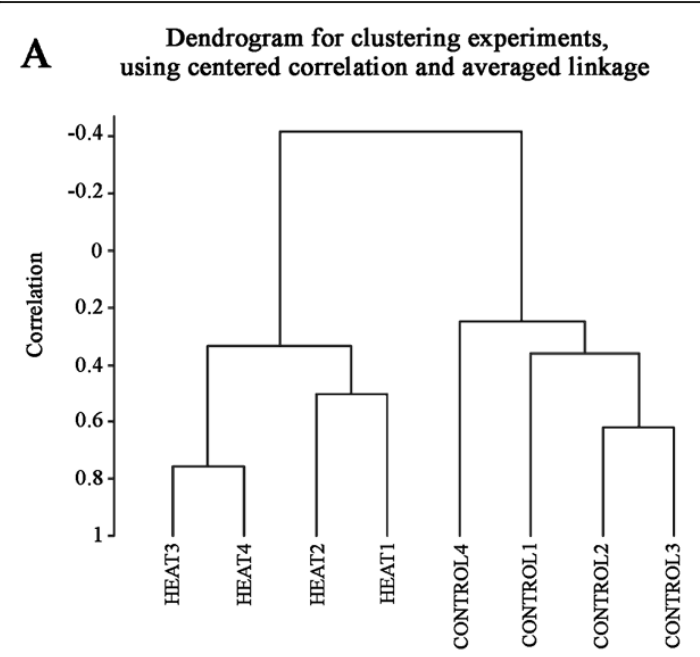

B

Volcano Plot

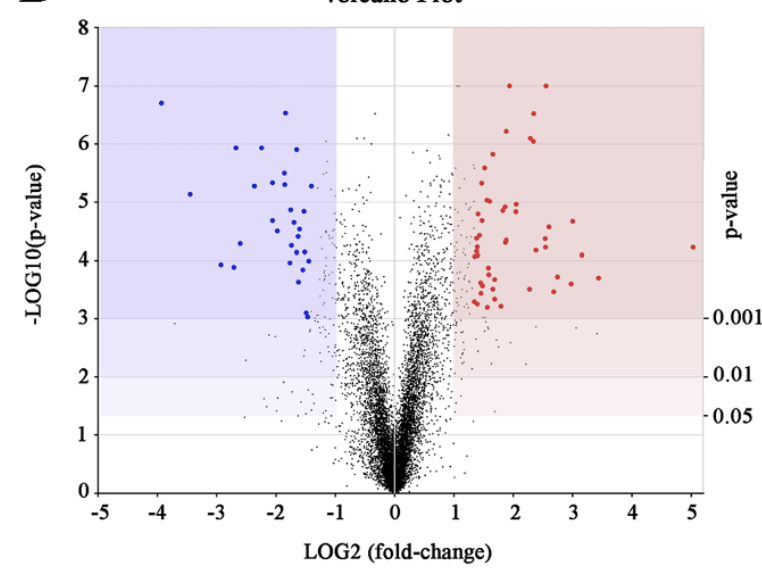

Figure 1 General microarray analysis. A) Dendrogram for clustering experiments using centered correlation and averaged linkage. The data from the 8 microarrays were included: 4 under control conditions and 4 after heat treatment. B) Volcano plot of the microarray results. Light blue region: significantly decreased expression, indicated a reduction of 50\%. Light red: region of increased expression, indicating a 2 -fold increase in gene expression compared to control. Three levels of significance are indicated by tone. Red and blue points represent the 80 genes that showed the largest changes in expression (10\% of the genes that change significantly at $P<0.001)$ under the heat treatment. the temperature changes in the regulation of gene expression.

Figure 1B provides a volcano plot of the microarray results. Both increased and decreased gene expression changes occurred due to heat treatment. The expression values that decreased by less than $1 / 2$ compared with the treatment are included in the blue area, while increases of more than two fold are shown in the light red region. In both regions, the genes that exhibited the greatest changes in expression due to the heat treatment have been marked with colored dots; these genes will be described below.

Next, we focused on three separate issues: a) ascertaining whether a given gene was expressed in the antennae in the experimental and control groups; b) obtaining a general overview of the genes whose expression was changed most due to the treatment and identifying the functional groups to which they belong; and c) determining the differences in the mean expression of particular groups of genes (olfactory and thermal stress-related) between the heat-treated and the control groups.

We note that a gene was considered to be expressed in the antennae in each group when it appeared as "Present" in the statistical detection calls for the four replicates in the group provided by the Affymetrix GeneChip microarray analysis software (see the RNA extraction and microarrays subsection in the Methods section).

The raw microarray data have been deposited in the following public database: ArrayExpress at the European Bioinformatics Institute (EBI), http://www.ebi.ac.uk/ arrayexpress; Accession number: E-MTAB-1228.

\section{Total gene expression in the third antennal segment in Drosophila}

The third antennal segments are the main olfactory receptor organs in Drosophila. These segments express genes related to olfactory reception as well as other genes with more general functions. As a first approach, we studied how many genes were expressed in the antennae. Of the 14,445 probe sets encoding a transcript in Drosophila, 7,774 (54\%) were expressed in the control group, while in the experimental group subjected to the heat treatment, 7,957 (55\%) were "Present" (Figure 2A). More than half of the genome was expressed in the Drosophila third antennal segment, showing the same range of gene expression (54\%-63\%) observed in the chemosensory appendages and even in other tissues (bodies) in Anopheles gambiae [25].

Based on the total values obtained, it appeared that heat might induce an increase of gene expression. To test this hypothesis, we analyzed the changes in gene expression levels due to heat treatment (Figure 2B). A total of 3,846 probe sets showed a change in expression 


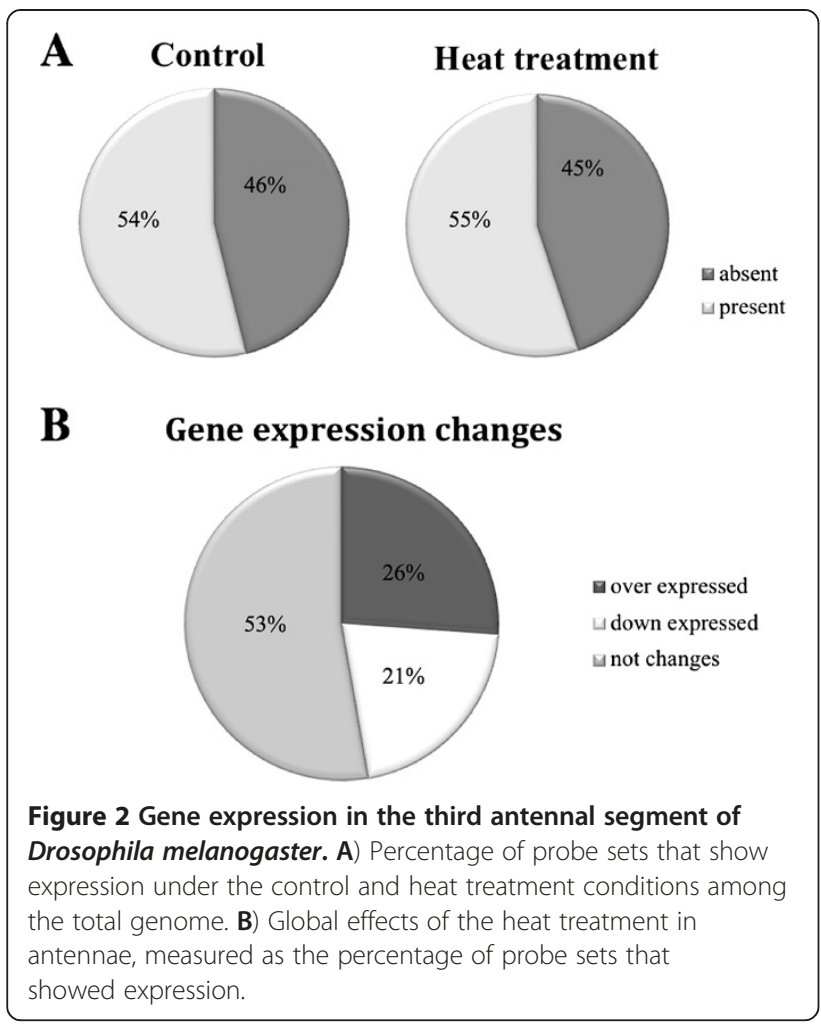

because of the treatment $(\mathrm{FDR}<0.1)$, among which 2,135 (26\%) increased, and 1,711 (21\%) decreased. Again, the overall expression levels appeared to be higher in the heat-treated than in the control group. However, both groups showed both increased and decreased gene expression after the heat treatment, thereby excluding the possibility of a general rule relating increased gene expression to temperature increases.

\section{Functional GO groups most affected by heat treatment}

To obtain an idea of the main functional processes affected by heat, we analyzed the genes whose expression showed the greatest changes following heat treatment. We studied a $10 \%$ of the genes that change significantly at $\mathrm{P}<0.001$. They undergo fold changes $>2.6$ including both increases and decreases in expression (Additional file 1: Table S1) for a total of 80 genes. As shown by the colored dots in Figure 1B, increased expression was observed for approximately $2 / 3$ of the genes, while a decrease was observed for approximately $1 / 3$.

These data are summarized in Figure 3 based on functional groups of GO biological process (information in GO molecular function and cellular component for each gene is also presented in Additional file 1: Table S1), distinguishing genes showing increased or decreased expression using different colors. Approximately $1 / 3$ of these genes have unknown functions. The other defined groups were represented by 4-9 genes each, with no obvious over-representation observed. The residual, heterogeneous group included 15 genes. As expected under heat treatment, many genes from the HSP family (6 genes), which are associated with the response to heat, were found on this list and were always overexpressed. The gene that presented the largest expression change was Hsp67b (fold change $>32$ ), followed by Hsp70Ab (> 10).

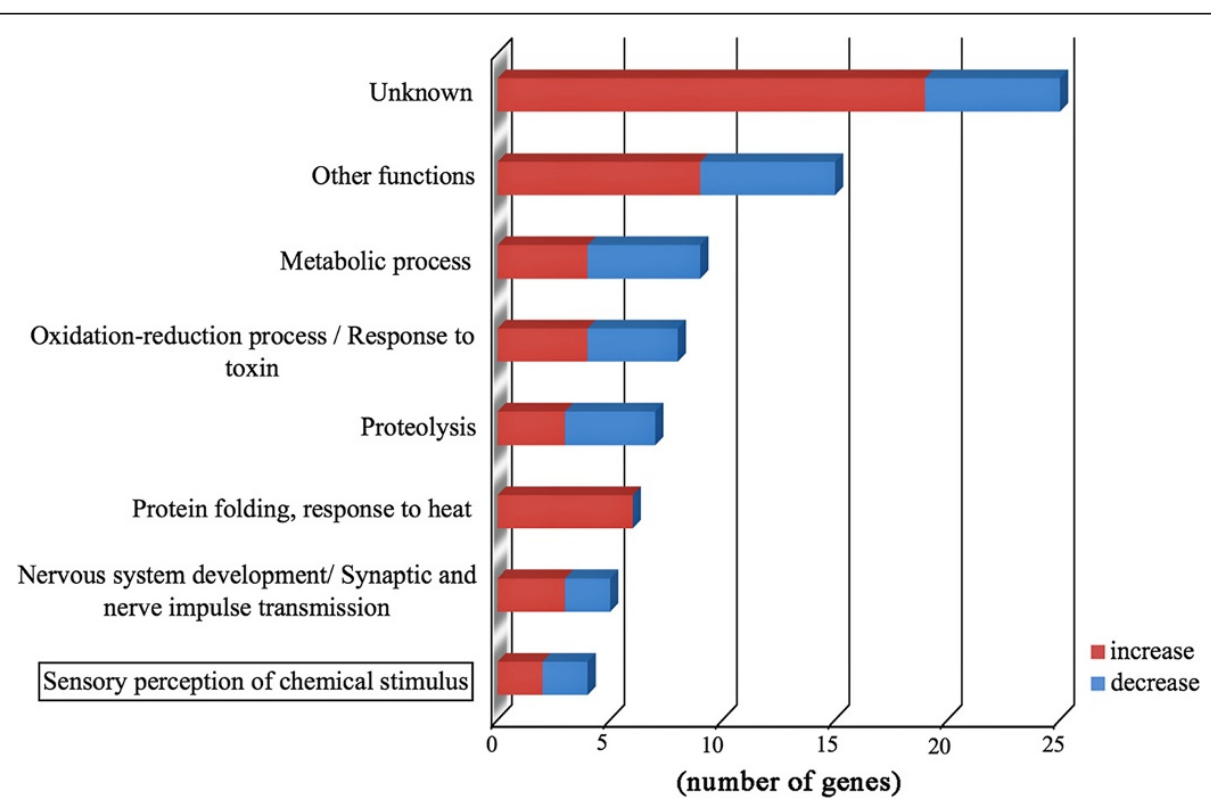

Figure 3 Gene Ontology (GO) groups based on biological process for the 80 genes that showed the greatest changes in expression under heat treatment. 
Additionally, some genes related to metabolic processes were present on the list (9 genes), but not all of these genes were overexpressed, indicating that both activation and inhibition of metabolic processes are important in the response to heat.

The detected genes corresponding to the sensory perception of chemical stimuli mainly encoded odorantbinding proteins ( 4 genes). In the group of oxidationreduction processes/responses to toxins, there were several genes previously associated with other perireceptor processes in olfactory reception, such as genes encoding members of the Cyp family (4 genes) and Glutathione-S -transferase. However, all of these groups included genes that were greatly over-expressed or strongly inhibited, and none of them showed a clear pattern of expression (Additional file 1: Table S1).

\section{Expression of olfactory and thermal stress genes}

To obtain a greater understanding of the molecular basis of the adaptation of olfactory reception to temperature and considering that small expression changes in key genes could affect olfaction beyond quantitative expectations, we studied particular groups of genes that encode elements that may affect "a priori" this process. A total of 389 genes were selected based on the literature (because in most cases, each gene was represented by a single probe set, the terms gene and probe set will be used interchangeably in the text). The complete gene list and the original results are included in Additional file 2: Table S2. Table 2 summarizes the results obtained for each of the following groups: a) genes related to thermal stress, including those encoding heat shock proteins (HSPs), cold shock domain proteins (CSDPs) and other thermal stressrelated genes; and b) genes related to olfactory reception, such as those encoding odorant binding proteins (OBPS), cytochrome P-450 mono-oxygenases (referred to as CYPs or P450 enzymes), UDP-Glucuronosyl transferases (UGTs), glutathione-S-transferases (GSTs), olfactory receptors (ORs and IRs), taste receptors (GRs), G-proteins, members of the cAMP signal transduction cascade and components of the IP3 pathway.

Among the 389 probe sets that were analyzed, 235 showed expression in at least the four samples from the experimental or the control groups. Of these 235 genes, a total of 95 exhibited modified expression in response to heat treatment, either presenting increased (52) or decreased (43) expression. In 8 out of the 14 groups, the changes within the group were coincident in their direction in all of the significant cases. However, for some groups, very few genes showed significant expression changes; this observation is described in further detail below.

\section{Genes related to thermal responses}

Several groups of genes have been associated with the response to different temperatures. They are related to the following products: heat shock proteins (HSPs); cold shock domain proteins (CSDPs), which are similar to those observed in the cold shock proteins (CSPs) of bacteria; and other genes related to the thermo-protection function.

In our study, we decided to include these genes as an internal control of appropriate heat treatment application

Table 2 Summary of the changes induced by the heat treatment in a group of $\mathbf{3 8 9}$ probe sets corresponding to a) thermal stress and b) olfactory reception genes

\begin{tabular}{|c|c|c|c|c|c|}
\hline & \multicolumn{5}{|c|}{ Number of genes showing expression differences at FDR $<0.1$} \\
\hline & Gene class & $\begin{array}{l}\text { Present/ } \\
\text { analyzed }\end{array}$ & $\begin{array}{l}\text { Total changes with heat } \\
\text { (\% of present) }\end{array}$ & $\begin{array}{c}\text { Over-expression } \\
\text { (\% of present) }\end{array}$ & $\begin{array}{c}\text { Down-expression } \\
\text { (\% of present) }\end{array}$ \\
\hline \multirow[t]{3}{*}{ Thermal stress } & HSPs & $18 / 26$ & $15(83 \%)$ & $15(83 \%)$ & $0(0 \%)$ \\
\hline & CSDPs & $3 / 4$ & $1(33 \%)$ & $0(0 \%)$ & $1(33 \%)$ \\
\hline & Other thermal genes & $15 / 27$ & $7(47 \%)$ & $2(13 \%)$ & $5(33 \%)$ \\
\hline \multirow[t]{12}{*}{ Olfactory reception } & OBPs & $19 / 47$ & $11(58 \%)$ & $7(37 \%)$ & $4(21 \%)$ \\
\hline & PBPRPs & $6 / 6$ & $3(50 \%)$ & $0(0 \%)$ & $3(50 \%)$ \\
\hline & CYPs & $54 / 84$ & $24(44 \%)$ & $10(18 \%)$ & $14(25 \%)$ \\
\hline & UGTs & $10 / 18$ & $3(30 \%)$ & $0(0 \%)$ & $3(30 \%)$ \\
\hline & GSTs & $17 / 20$ & $9(53 \%)$ & $5(29 \%)$ & $4(24 \%)$ \\
\hline & ORs & $38 / 40$ & $9(24 \%)$ & $4(11 \%)$ & $5(13 \%)$ \\
\hline & IRs & $13 / 16$ & $4(31 \%)$ & $4(31 \%)$ & $0(0 \%)$ \\
\hline & GRs & $11 / 66$ & $5(45 \%)$ & $3(27 \%)$ & $2(18 \%)$ \\
\hline & G-PROTEINS & $13 / 14$ & $2(15 \%)$ & $0(0 \%)$ & $2(15 \%)$ \\
\hline & AMPc pathway & $8 / 9$ & $1(12 \%)$ & $1(12 \%)$ & $0(0 \%)$ \\
\hline & IP3 pathway & $10 / 12$ & $1(10 \%)$ & $1(10 \%)$ & $0(0 \%)$ \\
\hline & TOTAL & $235 / 389$ & 95 (40\%) & $52(22 \%)$ & $43(18 \%)$ \\
\hline
\end{tabular}


in the experimental group because it is known that, especially for hsps, their expression levels increase with temperature [26-28].

In general, approximately half of the probe sets encoding products of response to heat stress showed increased expression, although there was also a significant fraction, approximately $17 \%$, that showed decreased expression. These data confirmed that the response to heat stress is mediated not only by the overexpression of certain thermo-protectors genes but also by the inhibition of the expression of others.

As for the different groups we studied, it should be noted that virtually all of the genes encoding HSPs present in the tissue displayed increased expression (15 out of 18 probesets) in individuals that were subjected to heat shock (Table 3 ). These results were expected if we consider the role this group of genes plays in protection against heat shock. Specifically, hsp 83 and DnaJ-1 (also known as hsp40), which showed significantly increased expression in the experimental group, have been related to the protection of synaptic transmission [29]. According to these results, the heat treatment was correctly applied to the flies.

As for the 4 genes of the CSDPs group, 3 of them, unr, yps and CG9705, are present on the antennae of adult individuals, but only CG9705 showed significant differences, decreasing its expression after applying the heat shock. We observed opposite expression behaviors of the heat and cold shock protein-encoding genes in response to temperature treatments, as was expected.

Finally, 7 other genes related to thermo-protection functions changed their expression significantly. However, they belong to a heterogeneous group, and the expression of these genes either increased or decreased. In this group, we include the genes anon-23 Da, smp-30, per, catsup, adh and two different transcripts of the gpdh gene, Fbtr0079147 and Fbtr0079146 (transcript annotation in Flybase), which displayed opposite expression behaviors in response to heat. Down regulation of per gene expression can be related to a previous study that reported delayed expression of the morning oscillation peak of per at high temperatures [30].

Table 3 Thermal stress genes

\begin{tabular}{|c|c|c|c|c|c|c|c|}
\hline Probe set ID & $p$ value & FDR & Gene symbol & $\begin{array}{l}\text { Expression level } \\
\text { (Control) }\end{array}$ & $\begin{array}{c}\text { Expression level } \\
\text { (Heat) }\end{array}$ & Fold-change & $\begin{array}{l}\text { Direction } \\
\text { of change }\end{array}$ \\
\hline \multicolumn{8}{|l|}{ HSPs } \\
\hline 1638872_at & $1.00 \mathrm{E}-07$ & $3.90 \mathrm{E}-05$ & hsp68 & 9.46 & 36.49 & 3.86 & $\uparrow$ \\
\hline 1641055_at & $2.66 \mathrm{E}-05$ & $1.15 E-03$ & hsp23 & 17.01 & 103.22 & 6.07 & $\uparrow$ \\
\hline 1629061_s_at & $6.03 \mathrm{E}-05$ & $1.73 \mathrm{E}-03$ & hsp67Bb/hsp22 & 7.58 & 246.51 & 32.54 & $\uparrow$ \\
\hline 1630487_s_at & $8.13 \mathrm{E}-05$ & 1.87E-03 & hsp67Bb/hsp22 & 5.43 & 48.74 & 8.98 & $\uparrow$ \\
\hline 1639571_s_at & $2.01 \mathrm{E}-04$ & 3.47E-03 & hsp70Ab/hsp70Aa & 12.20 & 133.08 & 10.91 & $\uparrow$ \\
\hline 1628117_at & $2.03 \mathrm{E}-04$ & $3.47 \mathrm{E}-03$ & hsp27 & 19.15 & 43.02 & 2.25 & $\uparrow$ \\
\hline 1635044_at & $3.41 \mathrm{E}-04$ & 4.93E-03 & hsp26 & 8.88 & 57.04 & 6.42 & $\uparrow$ \\
\hline 1641286_s_at & $7.26 \mathrm{E}-04$ & $9.14 \mathrm{E}-03$ & hsp60 & 634.29 & 1272.85 & 2.01 & $\uparrow$ \\
\hline 1636741_s_at & $1.32 \mathrm{E}-03$ & $1.32 \mathrm{E}-02$ & hsc70cb & 168.96 & 324.72 & 1.92 & $\uparrow$ \\
\hline 1626821_s_at & $1.45 \mathrm{E}-03$ & $1.35 \mathrm{E}-02$ & hsp70Ba/Bb/Bbb/Bc & 12.03 & 100.23 & 8.33 & $\uparrow$ \\
\hline 1637059_s_at & $5.34 \mathrm{E}-03$ & $3.23 E-02$ & dnaJ-1 & 1212.11 & 2323.72 & 1.92 & $\uparrow$ \\
\hline 1632841_x_at & $6.04 \mathrm{E}-03$ & $3.37 \mathrm{E}-02$ & hsp70Bc & 7.80 & 36.24 & 4.65 & $\uparrow$ \\
\hline 1630637_s_at & $1.30 \mathrm{E}-02$ & $5.97 \mathrm{E}-02$ & hsc70-4 & 6263.29 & 8913.44 & 1.42 & $\uparrow$ \\
\hline 1638484_at & $1.42 \mathrm{E}-02$ & $6.35 E-02$ & hsp67Bc & 4.91 & 7.03 & 1.43 & $\uparrow$ \\
\hline 1630688_at & $2.37 \mathrm{E}-02$ & $9.51 \mathrm{E}-02$ & hsp83 & 2870.70 & 5068.79 & 1.77 & $\uparrow$ \\
\hline \multicolumn{8}{|l|}{ CSDPs } \\
\hline 1639908_a_at & $3.30 \mathrm{E}-03$ & $2.22 \mathrm{E}-02$ & CG9705 & 309.24 & 248.56 & 0.80 & $\downarrow$ \\
\hline \multicolumn{8}{|c|}{ OTHER THERMAL GENES } \\
\hline 1638937_at & $1.49 \mathrm{E}-03$ & $1.35 \mathrm{E}-02$ & anon-23Da & 1998.45 & 1277.18 & 0.64 & $\downarrow$ \\
\hline 1635450_a_at & $1.72 \mathrm{E}-03$ & $1.52 \mathrm{E}-02$ & smp-30 & 440.83 & 358.12 & 0.81 & $\downarrow$ \\
\hline 1631333_s_at & $2.31 \mathrm{E}-03$ & $1.84 \mathrm{E}-02$ & $a d h$ & 212.45 & 699.39 & 3.29 & $\uparrow$ \\
\hline 1638452_at & $3.55 \mathrm{E}-03$ & $2.31 \mathrm{E}-02$ & per & 61.97 & 31.74 & 0.51 & $\downarrow$ \\
\hline 1627458_at & $5.72 \mathrm{E}-03$ & $3.24 \mathrm{E}-02$ & catsup & 330.68 & 259.13 & 0.78 & $\downarrow$ \\
\hline 1625949_at & $2.04 \mathrm{E}-02$ & $8.75 E-02$ & gpdh & 250.19 & 382.42 & 1.53 & $\uparrow$ \\
\hline 1634893_at & $2.33 \mathrm{E}-02$ & $9.48 \mathrm{E}-02$ & gpdh & 1118.48 & 989.07 & 0.88 & $\downarrow$ \\
\hline
\end{tabular}

Probe sets showing altered transcriptional regulation after heat treatment at FDR $<0.1$. 


\section{Genes encoding components of perireceptor events}

The so-called perireceptor events in olfactory reception occur in the lymph of the olfactory sensilla [31]. Odorant binding proteins (OBPS), Cytochrome P-450 monooxygenases (CYPs), UDP-Glucuronosyl transferases (UGTs) and glutathione-S-transferases (GSTs) are proteins that have been associated with these processes. In addition, some proteins related to the detection of pheromones that also function as OBPS have been described in other Drosophila species, which have been designated PBPRPs (Pheromone Binding Proteins-Related Proteins) and LUSH. We will also describe the analysis of these groups (Table 4).

Following the heat treatment, 47\% (50/106) of the probe sets related to proteins involved in perireceptor processes occurring in the antennae showed a change in gene expression. In $21 \%$ of the cases, gene expression increased, and in $26 \%$, it decreased.

Approximately 58\% (11/19) of the Obps genes present in the antenna presented a change in expression after heat treatment, although there was no single consistent pattern of change observed. Expression increased for 7 genes (obp 19b, obp57b, obp56e, obp56d, obp56a, obp44a, $o b p 57 c)$ and decreased for 4 (obp18a, obp57a, obp49a, obp83g). Attempts to classify the OBPs based on the specific odorants whose reception they mediate failed to clarify these results. It has been reported that OBPs function in a combinatorial manner [32], and there is some odorant overlap in the profiles of the following OBPs: a) obp18a and obp56a and b) 57a and 57b [33], which showed opposite expression responses to heat.

Among the genes involved in pheromone detection at the perireceptor level, the intensity values for the corresponding probe sets were extremely high, even under control conditions. In this study, there were 3 genes that showed significantly decreased expression after the heat treatment: pbprp4, pbprp3 and lush, the last two of which are expressed in the lymph of the trichoid sensilla [32].

The expression levels of other genes in this group also appeared to be reduced by heat treatment, although these differences were not significant. This reduction was in agreement with the changes reported in response to high concentrations of ethanol $[14,17]$.

There was a total of 24 genes encoding CYPs that showed altered expression in response to heat treatment (44\%), with expression increasing significantly for 10 of these genes and decreasing for 14 .

Of the genes encoding UGTs, 3 genes, ugt, ugt35a and ugt86Da, exhibited a small, but significant decrease in expression when subjected to heat shock, while the rest of the UGTs remained unchanged.

Finally, when we analyzed the GSTs, 5 genes, gstE5, gstD9, gstD3, gstE6 and gstD8, were found to show significantly increased expression when individuals were subjected to 48 hours of heat treatment, while 4 genes, gstD10, gstS1, gstE3 and gstD6, presented decreased expression. Increases in the expression of gst genes have been related to the development of chemical resistance in many insect species and mammalian systems [34] as well as in the development of alcohol preferences in rats $[13,34,35]$.

\section{Genes encoding molecular receptors}

Until 2009, the ORs were the only olfactory receptors that had been described in Drosophila [36,37]. However, another 3 taste receptors present in the antennae have now been reported to bind to odor molecules [38-40]: GR10a, GR21a and GR63a. In 2009, a new family of genes that encode ionotropic receptors, the IRS, was reported to function as molecular receptors involved in smell in Drosophila [41], and their olfactory profile was described [42]. In the present study, we analyzed all members of the three gene families described in antennae: the $o r$, $i r$ and $g r$ gene families.

After heat shock treatment, $29 \%$ of the probe sets for olfactory receptors showed a change in intensity (18\% increased, while $11 \%$ decreased) (Table 5).

If we separate the observations for all of the antennal or genes, only or $98 b$, which corresponds to the ab6B type ORN (olfactory receptor neuron), did not appear in any of the 8 arrays used here (Additional file 2: Table S2). Additionally, or $2 a$, of the at 3 ORN, was not found in some of the arrays and was therefore considered absent. The absence of these receptors in our samples was most likely due to the techniques and methods that were used here not being sufficiently sensitive to detect their messenger RNAs.

Among the or members present in our samples, 4 genes, or $47 b$, or $43 a$, or $13 a$ and or $88 a$, showed significantly increased expression under heat treatment, while 5 of them, or $22 b$, or $23 a$, or $69 a$, or $47 a$ and co-receptor or83b (now called orco) [43], presented decreased expression.

Although it initially appeared that there was no unique pattern of change regarding the expression of or genes in response to high temperatures, a common profile emerged when we considered the individual or members: 3 out of the 4 non-general or genes showing significantly decreased expression due to heat shock (or $22 b$, or69a and or47a) corresponded to basiconic sensilla (ab3, ab9 and ab5, respectively), while the ORs exhibiting increased expression (or47b, or $43 a$, or88a and 13a) corresponded to trichoid or intermediate sensilla (at4, at3, at4 and ai1). However, the correlation was not complete, and receptor or $23 a$, which showed downregulation under heat, was expressed in trichoid sensillum at2. 
Table 4 Olfactory reception genes: perireceptor events

\begin{tabular}{llllllll}
\hline Probe Set ID & $\mathrm{p}$ value & FDR & Gene symbol & Expression level (Control) & Expression level (Heat) & Fold-change & Direction of change \\
\hline OBPs & & &
\end{tabular}

\begin{tabular}{|c|c|c|c|c|c|c|c|}
\hline 1638374_at & 8.00E-07 & $1.56 \mathrm{E}-04$ & obp19b & 71.09 & 349.57 & 4.92 & $\uparrow$ \\
\hline 1625531_at & $1.37 \mathrm{E}-05$ & 1.01E-03 & obp18a & 85.63 & 25.49 & 0.30 & $\downarrow$ \\
\hline 1641288_at & $6.56 \mathrm{E}-05$ & $1.73 \mathrm{E}-03$ & obp57b & 372.95 & 541.16 & 1.45 & $\uparrow$ \\
\hline 1626586_at & $1.12 \mathrm{E}-04$ & $2.42 \mathrm{E}-03$ & obp57a & 213.04 & 62.81 & 0.30 & $\downarrow$ \\
\hline 1638276_at & $2.57 \mathrm{E}-04$ & $4.00 \mathrm{E}-03$ & obp56e & 31.87 & 252.05 & 7.91 & $\bar{\uparrow}$ \\
\hline 1623659_at & $8.67 \mathrm{E}-04$ & $1.04 \mathrm{E}-02$ & obp56d & 8517.02 & 14521.22 & 1.71 & $\bar{\uparrow}$ \\
\hline 1624074_at & 1.49E-03 & $1.35 \mathrm{E}-02$ & obp56a & 8.87 & 26.56 & 2.99 & $\uparrow$ \\
\hline 1639597_at & $1.80 \mathrm{E}-03$ & $1.56 \mathrm{E}-02$ & obp44a & 20.04 & 213.35 & 10.65 & $\bar{\uparrow}$ \\
\hline 1624932_at & $2.90 \mathrm{E}-03$ & $2.05 E-02$ & obp49a & 323.15 & 218.07 & 0.68 & $\downarrow$ \\
\hline 1634121_at & $2.97 \mathrm{E}-03$ & $2.07 E-02$ & obp57c & 1362.99 & 1686.91 & 1.24 & $\uparrow$ \\
\hline 1637914_at & $3.06 \mathrm{E}-03$ & $2.09 \mathrm{E}-02$ & obp83g & 48.67 & 22.39 & 0.46 & $\downarrow$ \\
\hline 1630963_at & $1.68 \mathrm{E}-04$ & $3.28 \mathrm{E}-03$ & pbprp4 & 7327.95 & 5218.26 & 0.71 & $\downarrow$ \\
\hline 1641200_at & $5.46 \mathrm{E}-03$ & $3.23 \mathrm{E}-02$ & pbprp3 & 22781.68 & 20750.76 & 0.91 & $\downarrow$ \\
\hline 1626882_at & $1.03 \mathrm{E}-02$ & $5.16 \mathrm{E}-02$ & lush & 9726.46 & 8670.25 & 0.89 & $\downarrow$ \\
\hline \multicolumn{8}{|l|}{ CYPs } \\
\hline 1634731_at & 9.70E-06 & $1.01 \mathrm{E}-03$ & сур $4 p 3$ & 26.01 & 78.50 & 3.02 & $\uparrow$ \\
\hline 1641428_at & $1.08 \mathrm{E}-05$ & $1.01 \mathrm{E}-03$ & сyp9c1 & 21.51 & 89.31 & 4.15 & $\uparrow$ \\
\hline 1636292_at & $2.07 \mathrm{E}-05$ & $1.01 \mathrm{E}-03$ & сур $313 a 4$ & 246.70 & 59.27 & 0.24 & $\downarrow$ \\
\hline 1640566_at & $2.07 \mathrm{E}-05$ & $1.01 \mathrm{E}-03$ & cyp4p2 & 6.68 & 14.72 & 2.21 & $\uparrow$ \\
\hline 1634640_at & $3.31 \mathrm{E}-05$ & $1.29 \mathrm{E}-03$ & cyp4ac1 & 41.66 & 18.62 & 0.45 & $\downarrow$ \\
\hline 1634662_at & 5.99E-05 & $1.73 \mathrm{E}-03$ & сур313a1 & 106.14 & 619.88 & 5.84 & $\uparrow$ \\
\hline 1630170_at & $2.05 E-04$ & $3.47 \mathrm{E}-03$ & сур12b2 & 97.66 & 72.44 & 0.74 & $\downarrow$ \\
\hline 1638562_a_at & $2.43 \mathrm{E}-04$ & $3.95 \mathrm{E}-03$ & cyp6d5 & 2273.70 & 1238.88 & 0.55 & $\bar{\downarrow}$ \\
\hline 1633639_at & $9.84 \mathrm{E}-04$ & $1.07 \mathrm{E}-02$ & cyp28d1 & 33.61 & 18.42 & 0.55 & $\downarrow$ \\
\hline 1629610_at & $1.29 \mathrm{E}-03$ & $1.32 \mathrm{E}-02$ & cyp28c1 & 481.27 & 236.01 & 0.49 & $\downarrow$ \\
\hline 1632114_at & $1.38 \mathrm{E}-03$ & $1.35 \mathrm{E}-02$ & cyp12a4 & 208.42 & 136.22 & 0.65 & $\downarrow$ \\
\hline 1637309_a_at & $1.88 \mathrm{E}-03$ & $1.59 \mathrm{E}-02$ & cyp12e1 & 39.93 & 58.32 & 1.46 & $\uparrow$ \\
\hline 1640755_at & $2.05 E-03$ & $1.66 \mathrm{E}-02$ & сур6а8 & 4012.95 & 1794.62 & 0.45 & $\downarrow$ \\
\hline 1639495_at & $2.58 \mathrm{E}-03$ & $1.94 \mathrm{E}-02$ & сур9b1 & 49.32 & 191.03 & 3.87 & $\bar{\uparrow}$ \\
\hline 1634143_at & $2.63 \mathrm{E}-03$ & $1.94 \mathrm{E}-02$ & cyp6w1 & 10481.51 & 7490.12 & 0.72 & $\downarrow$ \\
\hline 1626198_at & 2.85E-03 & $2.05 E-02$ & cyp4d8 & 765.77 & 539.45 & 0.70 & $\downarrow$ \\
\hline 1629009_at & $3.43 \mathrm{E}-03$ & $2.27 \mathrm{E}-02$ & cyp28a5 & 573.81 & 479.64 & 0.84 & $\downarrow$ \\
\hline 1623068_at & $5.40 \mathrm{E}-03$ & $3.23 \mathrm{E}-02$ & cyp4e3 & 215.36 & 153.79 & 0.71 & $\downarrow$ \\
\hline 1638053_at & 5.69E-03 & $3.24 \mathrm{E}-02$ & cyp4p1 & 314.86 & 382.49 & 1.22 & $\uparrow$ \\
\hline 1635008_at & $7.34 \mathrm{E}-03$ & $3.92 \mathrm{E}-02$ & cyp9b2 & 193.78 & 373.71 & 1.93 & $\bar{\uparrow}$ \\
\hline 1639539_at & $8.62 \mathrm{E}-03$ & $4.54 \mathrm{E}-02$ & cyp4e1 & 197.84 & 137.04 & 0.69 & $\downarrow$ \\
\hline 1623866_at & $9.54 \mathrm{E}-03$ & $4.96 \mathrm{E}-02$ & сур $4 a{ }^{2}$ & 683.94 & 428.93 & 0.63 & $\downarrow$ \\
\hline 1627974_at & $1.20 \mathrm{E}-02$ & $5.70 \mathrm{E}-02$ & cyp6t3 & 1226.10 & 2090.66 & 1.71 & $\bar{\uparrow}$ \\
\hline 1624101_at & $2.07 E-02$ & 8.76E-02 & сур6а23 & 49.59 & 70.99 & 1.43 & $\uparrow$ \\
\hline \multicolumn{8}{|l|}{ UGTs } \\
\hline 1624465_at & $7.97 \mathrm{E}-05$ & $1.87 \mathrm{E}-03$ & ugt & 163.99 & 101.28 & 0.62 & $\downarrow$ \\
\hline 1627662_at & $4.10 \mathrm{E}-04$ & $5.71 \mathrm{E}-03$ & ugt35a & 49.23 & 20.63 & 0.42 & $\downarrow$ \\
\hline 1624156_at & $1.93 \mathrm{E}-02$ & $8.35 \mathrm{E}-02$ & ugt86Da & 857.99 & 650.80 & 0.76 & $\downarrow$ \\
\hline \multicolumn{8}{|l|}{ GSTs } \\
\hline 1627890_at & 5.59E-05 & $1.73 \mathrm{E}-03$ & gstD10 & 57.17 & 17.23 & 0.30 & $\downarrow$ \\
\hline 1624732_at & $5.50 \mathrm{E}-04$ & $7.15 \mathrm{E}-03$ & gstE5 & 900.79 & 1707.24 & 1.90 & $\bar{\uparrow}$ \\
\hline
\end{tabular}


Table 4 Olfactory reception genes: perireceptor events (Continued)

\begin{tabular}{|c|c|c|c|c|c|c|c|}
\hline 1623957_s_at & $1.22 \mathrm{E}-03$ & $1.28 \mathrm{E}-02$ & gstS1 & 415.66 & 258.03 & 0.62 & $\downarrow$ \\
\hline 1626136_at & $1.91 \mathrm{E}-03$ & 1.59E-02 & gstD6 & 8.86 & 5.64 & 0.64 & $\downarrow$ \\
\hline 1636174_at & 2.36E-03 & $1.84 \mathrm{E}-02$ & gstD9 & 146.47 & 239.80 & 1.64 & $\uparrow$ \\
\hline 1635701_at & 5.67E-03 & $3.24 \mathrm{E}-02$ & gstD3 & 80.44 & 137.18 & 1.71 & $\uparrow$ \\
\hline 1634554_at & 7.15E-03 & 3.87E-02 & gstD8 & 482.07 & 677.21 & 1.41 & $\uparrow$ \\
\hline 1625744_at & $1.32 \mathrm{E}-02$ & 5.97E-02 & gstE6 & 1670.99 & 2452.98 & 1.47 & $\uparrow$ \\
\hline 1637129_at & 2.09E-02 & $8.78 \mathrm{E}-02$ & gstE3 & 1333.61 & 1054.64 & 0.79 & $\downarrow$ \\
\hline
\end{tabular}

Probe sets showing altered transcriptional regulation after heat treatment at $\mathrm{FDR}<0.1$.

On the other hand, down-regulation of the expression of a single gene, the common co-receptor orco, could control the number of ORs present in the membrane of the ORNs, according to its proposed role in directing receptor migration inside the cell [24]. Interestingly, a reduction of the level of orco expression has been reported in response to high concentrations of ethanol [14]. Because increasing temperature enhances the odorant concentration in the gas phase, these results may suggest that the co-receptor expression level may be involved in adaptation to high odorant concentrations.

Regarding the ir genes, we detected all of the previously described genes in the antenna, except ir $93 a$. Of the 13 probe sets that were detected, 4 genes, ir64a, ir $76 b$, ir $76 a$, ir $21 a$, showed significantly increased expression after heat shock, representing $30.77 \%$ of the total. A common pattern of increased gene expression in response to heat can be established for these genes. ir $76 b$ encodes the coreceptor of the ORNs of the four types of coeloconic sensilla, ac1-ac4, and may therefore influence odorant sensitivity in all of them. The gene products of ir64a and ir76a have been related to other co-receptors, IR8a in the sacculus and IR25a in sensilla ac4, respectively. Finally, ir21a has been reported to show expression at the arista and perhaps sacculus III. It has been noted that aristal neurons function as thermosensors [44], but the role of IR21a, if any, in mediating physiological responses to temperature changes, is unknown [42].

Finally, of the 66 probe sets related to $g r$ genes that were examined, only 11 were present in the antennal tissue; these included the three that were previously

Table 5 Olfactory reception genes: receptors

\begin{tabular}{|c|c|c|c|c|c|c|c|}
\hline Probe Set ID & $p$ value & FDR & Gene symbol & Expression level (Control) & Expression level (Heat) & Fold-change & Direction of change \\
\hline \multicolumn{8}{|l|}{ ORs } \\
\hline 1637114_at & 5.29E-04 & 7.12E-03 & or47b & 231.09 & 379.88 & 1.64 & $\uparrow$ \\
\hline 1631298_at & 8.79E-04 & $1.04 \mathrm{E}-02$ & or22b & 508.23 & 204.64 & 0.40 & $\downarrow$ \\
\hline 1638928_at & $7.12 \mathrm{E}-03$ & $3.87 \mathrm{E}-02$ & or23a & 82.61 & 70.27 & 0.85 & $\downarrow$ \\
\hline 1629154_at & $1.03 \mathrm{E}-02$ & $5.16 \mathrm{E}-02$ & or43a & 63.42 & 88.06 & 1.39 & $\uparrow$ \\
\hline 1636134_at & $1.07 \mathrm{E}-02$ & $5.26 \mathrm{E}-02$ & or83b & 5033.00 & 3735.63 & 0.74 & $\downarrow$ \\
\hline 1627819_at & $1.10 \mathrm{E}-02$ & 5.37E-02 & or13a & 10.90 & 19.34 & 1.78 & $\uparrow$ \\
\hline 1639973_a_at & $1.24 \mathrm{E}-02$ & 5.75E-02 & or69a & 24.90 & 18.72 & 0.75 & $\downarrow$ \\
\hline 1638902_at & $1.51 \mathrm{E}-02$ & $6.68 \mathrm{E}-02$ & or47a & 195.12 & 163.63 & 0.84 & $\downarrow$ \\
\hline 1631562_at & $2.16 \mathrm{E}-02$ & 8.94E-02 & or88a & 84.62 & 124.17 & 1.47 & $\uparrow$ \\
\hline \multicolumn{8}{|l|}{ IRs } \\
\hline 1633636_at & $3.11 \mathrm{E}-04$ & 4.67E-03 & ir64a & 280.42 & 452.47 & 1.61 & $\uparrow$ \\
\hline 1633365_at & 2.60E-03 & $1.94 \mathrm{E}-02$ & $i r 76 b$ & 144.09 & 218.73 & 1.52 & $\uparrow$ \\
\hline 1633880_s_at & $1.02 \mathrm{E}-02$ & $5.16 \mathrm{E}-02$ & ir76a & 107.47 & 139.77 & 1.30 & $\uparrow$ \\
\hline 1631795_at & 1.24E-02 & 5.75E-02 & $i r 21 a$ & 28.74 & 40.92 & 1.42 & $\uparrow$ \\
\hline \multicolumn{8}{|l|}{ GRs } \\
\hline 1629589_at & $1.56 \mathrm{E}-05$ & $1.01 \mathrm{E}-03$ & gr43a & 27.93 & 13.88 & 0.50 & $\downarrow$ \\
\hline 1629590_at & 9.78E-04 & 1.07E-02 & gr64c & 83.08 & 32.84 & 0.40 & $\downarrow$ \\
\hline 1631563_at & 4.25E-03 & $2.72 \mathrm{E}-02$ & gr21a & 39.53 & 65.82 & 1.67 & $\uparrow$ \\
\hline 1638594_at & 1.15E-02 & 5.56E-02 & gr28b & 15.88 & 20.39 & 1.28 & $\uparrow$ \\
\hline 1640888_a_at & 2.39E-02 & $9.51 \mathrm{E}-02$ & gr64e & 48.53 & 59.62 & 1.23 & $\uparrow$ \\
\hline
\end{tabular}

Probe sets showing altered transcriptional regulation after heat treatment at $\mathrm{FDR}<0.1$. 
described: gr10a, gr21a and gr63a. Among these genes, only gr21a, which is related to CO2 reception [39,40], showed a significant increase in expression associated with heat, while the other two exhibited no change. Of the other 8 probe sets present in the antenna, 4 showed a significant change in expression when Drosophila were subjected to heat shock, either increasing, as observed for $g r 28 b$ and gr64e, or decreasing, as observed for $g r 43 a$ and $g r 64 c$.

\section{Genes related to transduction cascades}

Although the direct involvement of transduction cascades in olfactory reception is still under discussion in Drosophila, some behavioral data suggest a role for the cAMP and DAG/IP3 pathways [45-47]. Therefore, we included some of the genes that mediate these processes in our analyses, such as genes encoding G-proteins and others related to either the cAMP or the DAG/IP3 cascade (Table 6).

The results of the analysis of the presence of G-proteins in antennae were in agreement with those reported in previous studies [48]. All of the genes encoding the alpha, beta and gamma subunits were expressed in the antenna, except for Gbeta76c and some transcripts of Galpha49B, a variant of Gqalpha. Two of these genes showed a significant change in expression following heat shock: Ggamma30A and Galpha73B (Gf). There were two probe sets encoding the first gene, one representing all known transcripts of the gene (Fbtr0079795, Fbtr0079796, Fbtr0079797) and another that encodes only one (Fbtr009797). Because the latter probe displayed low intensity values, indicating a lack of or very weak expression, the observed differences in gene expression must have been due to the action of the other transcripts (Fbtr0079795 and/or Fbtr0079796). Both Ggamma30A and Galpha73B showed decreased expression in the heat-treated group compared to control group.

Among the 9 genes in the cAMP pathway that were studied, only one gene encoding a protein kinase, $p k a-$ C3, showed a significantly higher intensity in the probe set after the heat shock treatment.
Finally, of the 12 probe sets related to the DAG/IP3 transduction cascade that were examined, dgkepsilon was the only gene that showed a significant difference, presenting increased expression in the heat-treated group compared to control group. The role of the dgkepsilon gene product also involves protein kinase activity. It has been proposed that the balance of phosphorylation is often critical for regulating enzyme function, mediating protein-protein interactions, altering the subcellular localization of proteins and controlling protein stability. Furthermore, kinases and phosphatases may work together to modulate the strength of a signal [49]. However, it must be kept in mind that transduction cascades mediate many cellular processes.

\section{Behavioral consequences of the changes in orco gene expression}

The microarray analysis identified a set of genes related to heat shock as well as olfaction that showed altered expression in response to temperature increases. To determine whether the expression changes observed for some of these genes can account for a portion of the previously described olfactory acclimation [6,7], we performed additional experiments.

First, we chose a single gene that may affect olfaction in a generalized manner. This type of gene is very difficult to find at the receptor level because of the combinatorial coding of olfactory information, which utilizes many olfactory receptors with differential specificities to capture a single odor. The orco gene encodes a coreceptor that dimerizes with the ORs and is expressed in more than $70 \%$ of ORNs [50]. Next, we attempted to simulate the change in expression that was produced by the heat treatment (a decrease for the orco gene) via genetic manipulation using RNAi and studied the behavioral consequences on olfaction (Figure 4B). Heatinduced olfactory sensitivity changes that were especially apparent at intermediate repellent concentrations were noted as a partial sensitivity loss [6].

Using a T-maze, we compared the response to $10^{-1.5}$ $\mathrm{vol} / \mathrm{vol}$ ethanol in water (the concentration that evoked

Table 6 Olfactory reception genes: transduction cascades

\begin{tabular}{lccccccc}
\hline Probe Set ID & p value & FDR & Gene symbol & Expression level (Control) & Expression level (Heat) & Fold-change & Direction of change \\
\hline G proteins & & & & & & \\
\hline 1637526_s_at & $6.65 E-05$ & $1.73 E-03$ & Ggamma30A & 94.79 & 45.06 & 0.48 & $\downarrow$ \\
\hline 1633439_at & $1.49 E-04$ & $3.06 E-03$ & Galpha73B & 213.15 & 94.02 & 0.44 \\
\hline AMPc pathway & & & & & 487.64 & 1.78 \\
\hline 1635928_a_at & $5.25 E-03$ & $3.23 E-02$ & pka-C3 & 274.00 & & 1 \\
\hline IP3 pathway & & & & & 170.57 & 1.20 & $\uparrow$ \\
\hline 1626289_at & $1.60 E-02$ & $7.03 E-02$ & dgkepsilon & 142.18 & & $\downarrow$ \\
\hline
\end{tabular}

Probe sets showing altered transcriptional regulation after heat treatment at $\mathrm{FDR}<0.1$. 

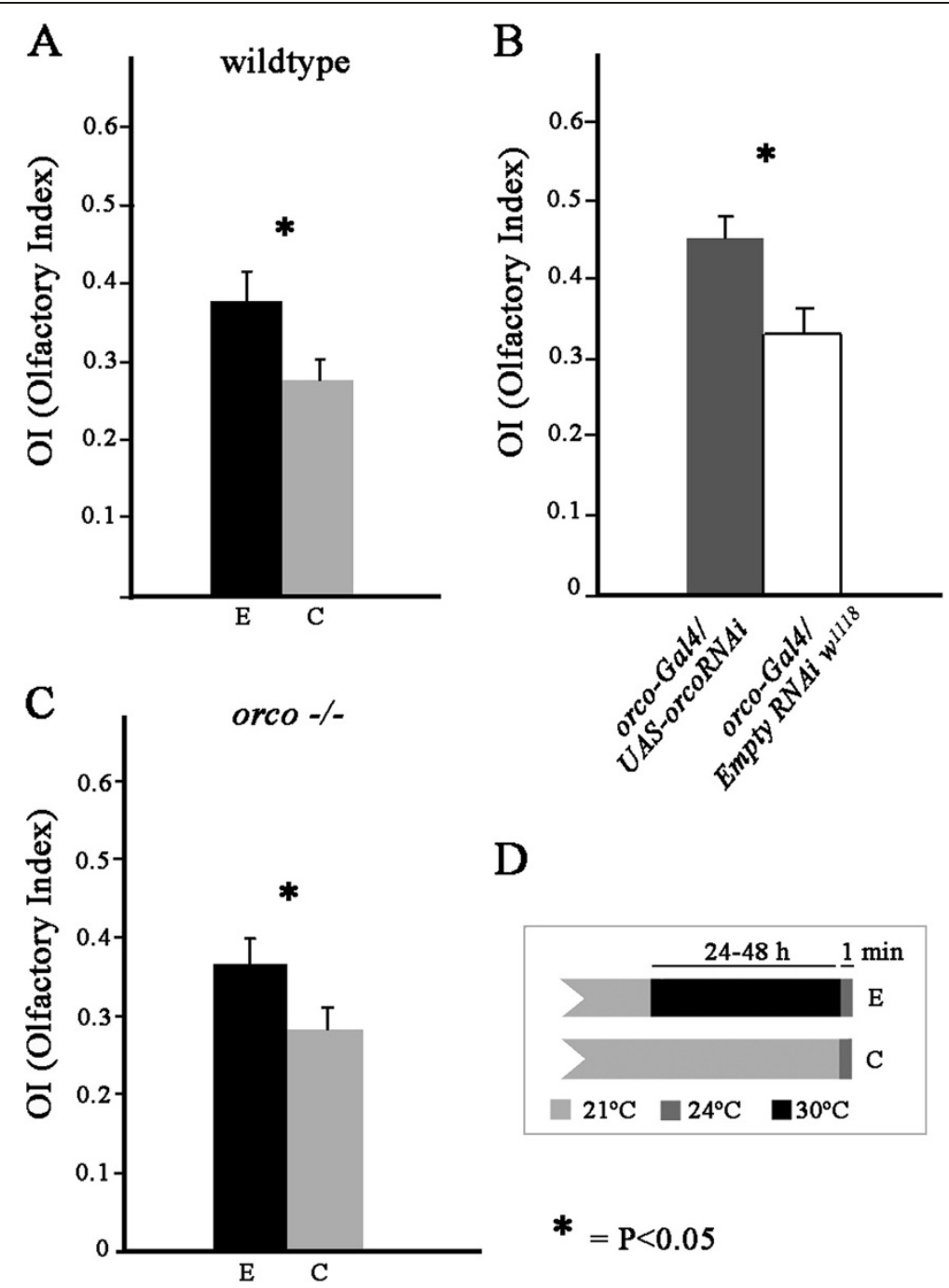

$\mathrm{D}$
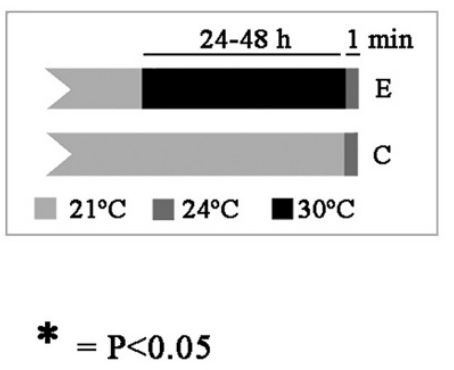

Figure 4 Changes in the olfactory preference in the T-maze due to heat. A) The repellent responses to $10^{-1.5}$ vol/vol ethanol in water are reduced in wildtype flies due to the heat treatment $[I \mathrm{O}=$ number flies on odor side/(number flies on odor + control sides); $1 \mathrm{O}>0.5$ indicates attraction, $\mathrm{IO}=0.5$ indicates indifference, and $0<\mathrm{IO}<0.5$ indicates repellency). B) Olfactory responses to $10^{-1.5}$ ethanol in flies with reduced levels of the Orco coreceptor compared with control flies of the same genetic background. C) The repellent responses to $10^{-0.5}$ ethanol are reduced in orco null mutants due to the heat treatment. D) Temperature protocol for the control C and experimental E flies shown in panels $\mathbf{A}$ ) and $\mathbf{C}$ ). Note that the behavioral response was measured for both groups at the same temperature and therefore at the same odorant concentration in the gas phase.

intermediate repellent responses in the control group) of flies showing reduced expression of orco (orco-Gal4/ UAS-orcoRNAi heterozygotes) with the corresponding control (orco-Gal4/line 6000) (Figure 4B). The repellent response was reduced in the experimental hybrids $\left(\mathrm{t}=2.527, \mathrm{nE}=34, \mathrm{nC}=39, \mathrm{P}=0.0137^{*}\right)$, as would be expected according to the results of the microarray analysis. This suggests that the conclusions of previous experiments showing that null orco mutants reduced very significantly the response to odorants [50] could be also applied to our experimental conditions by affecting the orco expression level. In the complete absence of the orco gene product, the Orco co-receptor, olfactory defects are observed because of the inability of the specific
ORs to localize to the dendritic surface of ORNs $[24,50]$. It is possible that altering the orco expression level may control ORN sensitivity in a quantitative manner by affecting the number of ORs that locate in the dendritic surface.

To explore the possibility that adaptation may occur in ORNs that express molecular receptors other than ORs, such as IRs, we studied the orco null mutant under normal conditions and after 24 hours of heat-shock treatment (previous experiments [6] showed that 6-48 h of heat shock have the same behavioral consequences, but we chose this treatment period here because it allows flies to retain a better condition regarding behavioral performance than under $48 \mathrm{~h}$ treatments). 
ORNs containing IRs appear to be less responsive to ethanol than those containing ORs [42]. Therefore, we had to block the responses through OR-dependent ORNs to observe IR dependent behavior.In this case, we increased the odorant concentration to $10^{-0.5} \mathrm{vol} / \mathrm{vol}$ ethanol in water to find the intermediate repellent response region in the control condition (with no heatshock treatment). The repellent responses to ethanol were reduced after heat shock (Figure 4C) in the same direction as previously described for normal flies after temperature acclimation. The differences were statistically significant: $\mathrm{t}=2.074, \mathrm{nE}=32, \mathrm{nC}=33, \mathrm{P}=0.0422 \%$. It therefore appears that the adaptation to temperature is not only dependent on the orco gene. The higher concentration required to achieve intermediate repellent responses and differences observed under heat shock may indicate that the orco null mutant exhibits reduced sensitivity compared to the wildtype control (as shown in Figure 4B) and that the other elements that mediate adaptation in this experiment made a relatively small quantitative contribution. However, we cannot exclude the possibility that differences in genetic background may play a role.

All of these results are consistent with the current understanding of olfactory reception. Ethanol is detected by the ORNs of the basiconic [51] and coeloconic sensilla [42], but with different specificities and effects. It has been reported that the overall responses to $10^{-2} \mathrm{vol} /$ vol ethanol in ORNs with ORs are excitatory, whereas the responses in ORNs with IRs appear to be inhibitory and less intense [42].

Thus, adaptation during the response to ethanol together with increasing temperatures could be mediated to a large extent by the basiconic sensilla, which show reduced expression of olfactory receptors, orco and particularly or genes. To a lesser extent, the coeloconic sensilla would adapt by increasing the expression of $i r$ genes (such as ir76a, which encodes the co-receptor for all the ORNs expressing IRs) that play an inhibitory role, as was shown in the microarray analysis.

\section{Conclusions}

The sense of smell adapts to changes in the environmental temperature via the adjustment of sensitivity in a direction that compensates for changes in the concentrations of odorous compounds in the gas phase due to their change in volatility [6]. Acclimation is initiated in the olfactory receptor organs [7]. To describe the mechanisms responsible for such adaptation, we performed a microarray analysis of the main olfactory receptor organs (the third antennal segments) of flies subjected to high temperatures compared with controls not subjected to temperature treatment.
Significant changes in the expression of genes related to the responses to heat and stress, such as increases in many genes in the heat shock protein family (HSPs) and decreases of some cold shock domain proteins (CSDPs), confirmed the efficiency of the applied treatment in the antennal tissue.

We also observed changes in gene expression concerning olfactory reception. The observation of genes related to perireceptor events, molecular olfactory receptors and transduction cascades before and after heat shock allowed us to glimpse certain gene expression patterns that might at least partially explain the observed functional changes.

It has been proposed that in Drosophila, olfactory reception takes place through several different routes $[42,52]$, which we will attempt to relate to our results. The basiconic, trichoid and coeloconic sensilla constitute a complex reception system, with each type of sensilla presenting its own characteristics according to its structure, the type of olfactory receptors expressed in its ORNs and the odorant type that it is able to detect.

General odor reception is performed in the basiconic sensilla and is mediated by ORs, which dimerize with the co-receptor Orco. The decreased sensitivity that has been reported at the behavioral level after heat shock could be associated with a decrease in the number of molecular receptors in the membranes of ORNs. In this work, we found that among the or genes whose expression was changed significantly after temperature treatment, there was a decreased response when they correspond to the ORNs of basiconic sensilla. Decreased expression has also been found for the ubiquitous Orco co-receptor, which is necessary for the transport and insertion of odorant receptors in the chemosensory dendritic membranes of olfactory neurons [50]. Interestingly, adaptation to high levels of ethanol has also been related to acute down-regulation of orco and other olfactory genes [13-15,17].

The only OBP that has been clearly localized to the basiconic sensilla is PBPR5 [53], and it showed no significant differences in expression due to heat.

In the trichoid sensilla, which mediate the response to pheromones in some cases [54], down-regulation of the expression of the specific odorant binding proteins LUSH and PBPRP3 has been found to be associated with increased temperatures or high concentrations of ethanol $[13-15,17]$. Therefore, in this type of sensilla, the control mechanism causing the system to become less sensitive may begin with a change in the solubility of pheromones in the lymph surrounding the ORNs. Among the ORs expressed in the ORNs of trichoid sensilla, we observed that when they showed a change in expression under heat treatment, it was in the form of an increase (with one exception being observed, for an OR of at2). This change in expression appears to occur 
in the opposite direction compared to the basiconic sensilla. However, these ORs preferably show inhibitory responses in empty neurons [51], indicating either that they mediate actual inhibitory responses or that they function in a different way. Thus, for the at1 sensilla, an inhibitory-excitatory relationship has been suggested between LUSH and SNMP and the Or67d/Orco elements of this system. Moreover, different responses have been recorded when Or67d has been expressed in trichoid or basiconic sensilla [52]. In the present study, neither SNMP nor or67d showed a significant change in expression, but decreases in LUSH and Orco could control the entire system.

The coeloconic sensilla contain ORNs that express different types of olfactory receptors, the Irs. They play a role that is complementary to olfaction through the ORs [42]. Whether the response of the Ir system is to specific or common compounds, it preferentially displays inhibitory responses. Interestingly, microarray analysis found some differences in the gene expression response to heat, always in the direction of up-regulation. One of the genes that exhibited a change in expression has been described as the co-receptor for ORNs containing Irs. In this case, an increased number of molecular receptors inducing more inhibitory responses might confer the same result as the decrease of the excitation of basiconic sensilla.

There are also a few changes related to transduction cascade genes that could be contributing to olfactory modulation in the acclimation to high temperatures.

Achieving a better understanding of the basic mechanisms of olfactory reception in the future may help to explain the differences observed in other genes related to perireceptor events; in most cases, these genes failed to show a uniform pattern. For example, the genes encoding CYPs and GSTs showed both up- and downregulation, and among the UGTs, there were only 3 genes presenting significantly decreased expression.

\section{Methods}

\section{Drosophila stocks and heat treatment}

The standard Canton-S line of Drosophila melanogaster, obtained from the Bloomington Stock Center (BSC, Indiana, USA), was used in the experiments. The flies were bred at $21 \pm 1^{\circ} \mathrm{C}$, with light/dark cycles of $12: 12$ hours in 220 cc. bottles with a common yeast-sugar-agar medium. In the experimental group, 2-to-8-day-old flies were maintained for $48 \mathrm{~h}$ at $30^{\circ} \mathrm{C} \pm 1^{\circ} \mathrm{C}$. For the control group, the flies remained at the initial growing temperature. Before the treatment experimental and control flies were transferred to new bottles with a near-odorless medium composed of $5 \mathrm{~g} / \mathrm{l}$ agarose, $50 \mathrm{~g} / \mathrm{l}$ sucrose and water. This measure was adopted in an attempt to minimize the differential effects of environmental odor in the experimental group versus the control.

For the behavioral validation of the effects of the or83b (orco) gene, the following stocks were used: a natural population (P2), that exhibits the same olfactory phenotype in response to heat as the standard wildtype stocks Canton-S and Lausanne-S (Riveron et al., 2009); an orco null mutant $(w[*]) ; w\left[+^{*}\right]$ orco [2] (BSC, donated by L. Vosshall, Rockefeller University, New York, USA); orco-Gal4 ( $w$; P\{orco-GAL4.W\}11.17; TM2/TM6B, Tb1, donated by Vosshall), modified by the substitution of the third chromosome with the wildtype chromosome of the $w$ [1118] stock of the Exelixis collection (Harvard, USA); UAS-OrcoRNAi; and line 60000, which corresponds to the $w[1118]$ isogenic host strain for the RNAi library, (VDRC, Vienna).

\section{RNA extraction and microarrays}

Four independent replicate tests were performed for each temperature regime (heat or control), and the tests were processed in different batches. In each batch, we included samples from each of the groups to randomize factors other than the applied treatment that may affect gene expression. The third antennal segments were obtained by freezing flies in liquid nitrogen, followed by fracturing and specimen collection. A large number of samples (approximately 4,000 third antennal segments for each replicate) was collected to achieve a sufficient representation of genes with low expression levels that could be missed using other protocols. Each replicate contained 2 groups of 2,000 segments collected from $11: 00$ to $14: 00$ and $16: 00$ to $19: 00$ to prevent the misassignment of gene expression due to circadian fluctuations.

Total RNA was purified with the Nucleospin RNA II kit (Macherey-Nagel), following the manufacturer's instructions. The GeneChip Drosophila Genome 2.0 Array developed by Affymetrix (Santa Clara, CA, USA) was used in the analyses. This array contains 18,800 probe sets, corresponding to over $13500 \mathrm{D}$. melanogaster genes. RNA processing, hybridization and scanning were performed at the Laboratory of Molecular Oncology, HUCA (Asturias, Spain), according the manufacturer's instructions, from $3 \mu \mathrm{g}$ of total RNA for each of the 8 samples.

Normalization, filtering and statistical analysis were conducted. Each Affymetrix GeneChip probe set contains 8 to 16 paired perfect match (PM) and mismatch (MM) 25-mer probes, which are used to determine whether a given gene is expressed and to measure the expression level (signal) [55]. The Affymetrix Microarray Suite version 5 (MAS5) algorithm uses the probe-pair data to calculate the detection calls. MAS5 employs a non-parametric statistical test (Wilcoxon signed rank test) of whether 
significantly more perfect matches show a stronger hybridization signal than their corresponding mismatches to produce the detection call Absent (A) or Present (P) [56].

Moreover, for each probe, we set the signal intensity to reflect the relative expression of the related transcript. In this study, only probe sets with detectable expression (P) in all four replicates of the analyzed group (heat or control) were considered "Present" in that group.

The complete microarrays were used to obtain general information on the gene expression levels present in the third antennal segment and for the analysis of GO groups among the 100 genes showing the most significant changes associated with heat treatment. For further analysis, 389 genes previously related to thermal changes and olfactory reception according to current functional annotations of the Drosophila gene set were selected. Only these data were analyzed in detail, as for the custom-made microarrays [12].

The data were GC-RMA normalized with Bioconductor and the $R$ project for statistical computing [57] using the BRB-Tools program developed at the Biometric Research Branch of the Division of Cancer Treatment \& Diagnosis of the National Cancer Institute (Maryland, USA).

The probe sets were compared between groups of arrays using t-tests for each probe set independently, based on the normalized log-ratios for the cDNA arrays and the normalized log-intensities for the one-color oligonucleotide arrays. In the analysis, the probabilistic p-value and false discovery rate (FDR) [58] were obtained. Regarding the FDR values, an increase and/or decrease in a given gene's expression level was considered significant if the associated value was equal to or lower than 0.1. To analyze the changes in the expression intensity of a given probe set between the control and temperature-treated groups, fold-change values were also obtained. Because the modulation due to temperature was not expected to produce extreme expression fold changes, we used the FDR 0.1 value to limit type II error (not recognizing a true effect as significant). This setting is common when microarray analysis is applied to specific tissues or cell cultures [59-61].

\section{RT-PCR}

Total RNA from the third antennal segments of the flies in the heat-treated and control groups was isolated as described previously, and first strand cDNA was synthesized from the total amount of isolated RNA using the SuperScript first-strand synthesis system for reverse transcriptase-PCR (Invitrogen) with random primers.

Real-time PCR was performed in the 7900HT Fast Real-Time PCR System (Applied Biosystems), and cycle thresholds (CTs) were determined using SDS 2.3 software (Applied Biosystems). Each reaction was carried out with 3 replicates for each pair of primers and each condition in a final volume of $15 \mu \mathrm{l}$ using SYBR Green ${ }^{\odot}$ Master Mix (Applied Biosystems).

Primers (Table 7) were designed to join the end of one exon with the beginning of the next exon and were previously tested in silico for their ability to amplify cDNA products and not genomic DNA. Each pair of primers was tested together with the pair corresponding to Btubulin60D, which was used as a control to ensure an equal amplification efficiency by comparing the slopes of the obtained standard curves. Data analysis was carried out following the $\Delta \Delta \mathrm{CT}$ method [62].

Correspondence between the microarray and the q-PCR data for the same 9 genes was analyzed by regression line and correlation value. Statistical significance was determined by comparing regression and residual variances using an ANOVA test.

\section{Olfactory behavior, T-maze}

A T-maze $[63,64]$ was used to test olfactory behavior. This assay is performed in complete darkness and is a double-choice olfactory preference test. Briefly, 30 flies from the experimental or control groups were starved for 24 hours before the test. They were then introduced into a central chamber in a sliding vertical plate from the starting compartment. Once the plate was placed in

Table 7 Primer sequences for the RT-PCR validation experiment

\begin{tabular}{lll}
\hline Gene & Forward primer & Reverse primer \\
\hline gr21a & CTGCTTCTGCAGCTTGTGGT & TAAGTGGCGATGATCGTTGT \\
\hline hsc70Cb & ATCGGTCAGACGACAAGGAG & CGAAGGCCACAAAGGAGG \\
\hline hsp67Bb & CCAGCATCAATATACCCTTGG & TGGCAATTTCTCTGCTTCC \\
\hline obp $19 a$ & CCTTCACCGGAAAATACTCG & CTCCCAGCCACCATTGTTC \\
\hline or47b & GTCGGGTTCTGCCTGAATG & GGCGGAGTCATGTCAAACTT \\
\hline pbprp4 & TGAGCCACCTCCACTGACTG & GGCCAGTTCTCCCTGATTT \\
\hline per & AGTTCATAACGTCGATGACCA & TCATCAAACCGGACTTTCG \\
\hline ugt86Da & GATCAAGAGCAGCTACAAGGTTC & GAGGTCCTCGTGGTGGTAGA \\
\hline Btubulin60D & AACACCGATCTGGTGGAT & GCGCGGCAGATAGAAGTAGT \\
\hline
\end{tabular}


the bottom position, the flies could choose between the left and right sides, containing the odorant tube and the control tube, during the 1-minute experiment. The odorant tube contained a piece of filter paper soaked with $0.5 \mathrm{ml}$ of ethanol at a certain concentration, and the other side contained the solvent, water.

The olfactory index (OI) was calculated as the number of flies in the stimulus tube divided by the total number of flies at either end. The OI values ranged from 0 (maximum repulsion) to 1 (maximum attraction), with the threshold of indifference being 0.5 .

In our experiments, the olfactory stimulus was ethanol (Merck, Darmstadt, Germany) diluted in water. The odorant concentration for each experiment was chosen based on the ability of a given concentration to evoke intermediate repellent responses. This is the region of the dose-response curve that gave us a maximal resolution in distinguishing sensitivity differences associated with heat shock in a previous study [6]. This concentration was $10^{-1.5}(\mathrm{vol} / \mathrm{vol})$ in the experiment involving flies showing reduced expression of the orco gene due to the effect of RNAi in heterozygous orco-Gal4/UAS-orcoRNAi flies and $10^{-0.5}$ in the experiment with the orco null mutant.

More than 30 replicate tests were performed for each line and condition; the exact number in each case is indicated in the Results section. Statistical significance was determined using Student's t-test.

\section{Additional files}

Additional file 1: Table S1. Table listing the 80 genes that showed the greatest changes in expression in response to heat (10\% of the genes that change significantly at $\mathrm{P}<0.001$ ), either increasing (black) or decreasing (blue). In both cases the fold change correspond to the ratio of the more abundant to the less abundant group, with or without heat treatment.

Additional file 2: Table S2. Table listing the results for the 389 probe sets that were included in the detailed microarray analysis. The raw microarray data have been deposited in the following public database: ArrayExpress at the European Bioinformatics Institute (EBI), http://www. ebi.ac.uk/arrayexpress. MAGE-TAB Accession number: E-MTAB-1228.

\section{Abbreviations}

CSDP: Cold shock domain protein; CYP: Cytochrome P-450 mono-oxygenase; FDR: False discovery rate; GR: Taste receptor; GST: Glutathione-S-transferase; HSP: Heat shock protein; IR: Variant ionotropic chemosensory receptor; OBP: Odorant binding protein; OR: Olfactory receptor; ORN: Olfactory receptor neuron; UGT: UDP-Glucuronosyl transferase.

\section{Competing interests}

The authors declare that they have no competing interests.

\section{Authors' contributions}

JR performed the microarray experiments and analysis and contributed to the experimental design and preparation of the manuscript. TB designed and performed the quantitative-PCR validation and contributed to the preparation of the manuscript. EA participated in the experimental design and analysis, directed the work and prepared the manuscript. All authors read and approved the final manuscript.

\section{Acknowledgements}

We thank JG Sørensen for his advice regarding the data analysis. This work was supported by the Spanish Ministries of Education and Science (BFU200504525), Science and Innovation (BFU2008-01256) and FEDER Founds. J.R. was a predoctoral fellow of the Science, Technology and Innovation Program of the Principado de Asturias, and T.B. was a predoctoral FPU fellow of the Spanish Ministry of Education and Science.

\section{Author details}

'Department of Functional Biology, Faculty of Medicine, University of Oviedo, Oviedo 33006, Spain. ${ }^{2}$ Present address: Vector Group, Liverpool School of Tropical Medicine, Pembroke PI, Liverpool, Merseyside L3 5QA, UK. ${ }^{3}$ Present address: Department of Neuroscience, The Scripps Research Institute, Jupiter, Florida 33458, USA.

Received: 10 August 2012 Accepted: 5 April 2013

Published: 17 April 2013

\section{References}

1. Dalton P: Psychophysical and behavioral characteristics of olfactory adaptation. Chem Senses 2000, 25:487-492.

2. Devaud JM, Acebes A, Ferrus A: Odor exposure causes central adaptation and morphological changes in selected olfactory glomeruli in Drosophila. J Neuroscience 2001, 21:6274-6282.

3. Devaud JM, Acebes A, Ramaswami M, Ferrús A: Structural and functional changes in the olfactory pathway of adult Drosophila take place at a critical age. J Neurobiol 2003, 56:13-23.

4. Stortkuhl KF, Hovemann BT, Carlson JR: Olfactory adaptation depends on the trp Ca2+ channel in Drosophila. J Neuroscience 1999, 19:4839-4846.

5. Deshpande M, Venkatesh K, Rodrigues V, Hasan G: The inositol 1,4, 5- trisphosphate receptor is required for maintenance of olfactory adaptation in Drosophila antennae. J Neurobiol 2000, 43:282-288.

6. Riveron J, Boto T, Alcorta E: The effect of environmental temperature on olfactory perception in Drosophila melanogaster. I Insect Physiol 2009, 55:943-951.

7. Martin F, Riveron J, Alcorta E: Environmental temperature modulates olfactory reception in Drosophila melanogaster. I Insect Physiol 2011, 57:1631-1642

8. Sørensen JG, Loeschcke V: Studying stress responses in the post-genomic era: its ecological and evolutionary role. J Biosci 2007, 32:447-456.

9. Telonis-Scott M, Hallas R, McKechnie SW, Wee CW, Hoffmann AA: Selection for cold resistance alters gene transcript levels in Drosophila melanogaster. J Insect Physiol 2009, 55:549-555.

10. Laayouni H, García-Franco F, Chávez-Sandoval BE, Trotta V, Beltran S, Corominas M, Santos M: Thermal evolution of gene expression profiles in Drosophila subobscura. BMC Evol Biol 2007, 7:42.

11. Turner TL, Levine MT, Eckert ML, Begun DJ: Genomic analysis of adaptive differentiation in Drosophila melanogaster. Genetics 2008, 179:455-473.

12. Zhou S, Stone EA, Mackay TF, Anholt RR: Plasticity of the chemoreceptor repertoire in Drosophila melanogaster. PLoS Genet 2009, 5:e1000681.

13. Awofala AA: Genetic approaches to alcohol addiction: gene expression studies and recent candidates from Drosophila. Invert Neurosci 2011, 11:1-7.

14. Morozova TV, Anholt RR, Mackay TF: Transcriptional response to alcohol exposure in Drosophila melanogaster. Genome Biol 2006, 7:R95.

15. Morozova TV, Anholt RR, Mackay TF: Phenotypic and transcriptional response to selection for alcohol sensitivity in Drosophila melanogaster. Genome Biol 2007, 8:R231.

16. Morozova TV, Goldman D, Mackay TF, Anholt RR: The genetic basis of alcoholism: multiple phenotypes, many genes, complex networks. Genome Biol 2012, 13:239.

17. Kong EC, Allouche L, Chapot PA, Vranizan K, Moore MS, Heberlein U, Wolf FW: Ethanol-regulated genes that contribute to ethanol sensitivity and rapid tolerance in Drosophila. Alcohol Clin Exp Res 2010, 34:302-316.

18. Dana AN, Hong YS, Kern MK, Hillenmeyer ME, Harker BW, Lobo NF, Hogan $J R$, Romans P, Collins FH: Gene expression patterns associated with blood-feeding in the malaria mosquito Anopheles gambiae. BMC Genomics 2005, 6:5.

19. Hahn MW, Lanzaro GC: Female-biased gene expression in the malaria mosquito Anopheles gambiae. Curr Biol 2005, 15:R192-R193.

20. Warr C, Clyne P, de Bruyne M, Kim J, Carlson JR: Olfaction in Drosophila: coding, genetics and e-genetics. Chem Senses 2001, 26:201-206. 
21. Félix $R C$, Müller $P$, Ribeiro $V$, Ranson $H$, Silveira $H$ : Plasmodium infection alters Anopheles gambiae detoxification gene expression. BMC Genomic 2010, 11:312.

22. Biessmann H, Nguyen QK, Le D, Walter MF: Microarray-based survey of a subset of putative olfactory genes in the mosquito Anopheles gambiae. Insect Mol Biol 2005, 14:575-589.

23. Marinotti $\mathrm{O}$, Nguyen $\mathrm{QK}$, Calvo E, James AA, Ribeiro JM: Microarray analysis of genes showing variable expression following a blood meal in Anopheles gambiae. Insect Mol Biol 2005, 14:365-373.

24. Benton R, Sachse S, Michnick SW, Vosshall LB: Atypical membrane topology and heteromeric function of Drosophila odorant receptors in vivo. PLOS Biol 2006, 4:e20.

25. Pitts RJ, Rinker DC, Jones PL, Rokas A, Zwiebel L: Transcriptome profiling of chemosensory appendages in the malaria vector Anopheles gambiae reveals tissue- and sex-specific signatures of odor coding. BMC Genomics 2011, 12:271.

26. Craig EA: The heat shock response. CRC Crit Rev Biochem 1985, 18:239-280.

27. Feder ME, Hofmann GE: Heat-shock proteins, molecular chaperones, and the stress response: Evolutionary and ecological physiology. Annu Rev Physiol 1999, 61:243-282

28. Sørensen JG, Kristensen TN, Loeschcke V: The evolutionary and ecological role of heat shock proteins. Ecol Lett 2003, 6:1025-1037.

29. Neal SJ, Karunanithi S, Best A, So AK, Tanguay RM, Atwood HL, Westwood JT: Thermoprotection of synaptic transmission in a Drosophila heat shock factor mutant is accompanied by increased expression of $\mathrm{Hsp} 83$ and DnaJ-1. Physiol Genomics 2006, 25:493-501.

30. Bywalez W, Menegazzi P, Rieger D, Schmid B, Helfrich-Förster C, Yoshii T: The dual-oscillator system of Drosophila melanogaster under natural-like temperature cycles. Chronobiol Int 2012, 29:395-407.

31. Pelosi P: Perireceptor events in olfaction. J Neurobiol 1996, 30:3-19.

32. Shanbhag SR, Hekmat-Scafe D, Kim MS, Park SK, Carlson JR, Pikielny C, Smith DP, Steinbrecht RA: Expression mosaic of odorant-binding proteins in Drosophila olfactory organs. Microsc Res Tech 2001, 55:297-306.

33. Swarup S, Williams TI, Anholt RR: Functional dissection of Odorant binding protein genes in Drosophila melanogaster. Genes Brain Behav 2011, 10:648-657.

34. Waxman DJ, Azaroff L: Phenobarbital induction of cytochrome P-450 gene expression. Biochem J 1992, 281:577-592.

35. Bjork K, Saarikoski TS, Arlinde C, Kovanen L, Osei-Hyiaman D, Ubaldi M, Reimers M, Hyytia P, Heilig M, Sommer WH: Glutathione-S-transferase expression in the brain: possible role in ethanol preference and longevity. FASEB J 2006, 20:1826-1835.

36. Clyne P, Warr C, Freeman M, Lessing D, Kim J, Carlson JR: A novel family of divergent seven-transmembrane proteins: candidate odorant receptors in Drosophila. Neuron 1999, 22:327-338.

37. Vosshall L, Amrein H, Morozov P, Rzhetsky A, Axel R: A spatial map of the olfactory receptor expression in the Drosophila antenna. Cell 1999, 96:725-736.

38. Scott K, Brady R Jr, Cravchik A, Morozov P, Rzhetsky A, Zuker C, Axel R: A chemosensory gene family encoding candidate gustatory and olfactory receptors in Drosophila. Cell 2001, 104:661-673.

39. Jones WD, Cayirlioglu P, Kadow IG, Vosshall LB: Two chemosensory receptors together mediate carbon dioxide detection in Drosophila. Nature 2007, 445:86-90.

40. Kwon JY, Dahanukar A, Weiss LA, Carlson JR: The molecular basis of CO2 reception in Drosophila. Proc Natl Acad Sci U S A 2007, 104:3574-3578.

41. Benton R, Vannice KS, Gomez-Diaz C, Vosshall LB: Variant ionotropic glutamate receptors as chemosensory receptors in Drosophila. Cell 2009, 136:149-162.

42. Silbering AF, Rytz R, Grosjean Y, Abuin L, Ramdya P, Jefferis GS, Benton $R$ : Complementary function and integrated wiring of the evolutionarily distinct Drosophila olfactory subsystems. J Neurosci 2011, 31:13357-13375.

43. Vosshall LB, Hansson BS: A unified nomenclature system for the insect olfactory co-receptor. Chem Senses 2011, 36:497-498.

44. Gallio M, Ofstad TA, Macpherson LJ, Wang JW, Zuker CS: The coding of temperature in the Drosophila brain. Cell 2011, 144:614-624.

45. Martin F, Charro MJ, Alcorta E: Mutations affecting the CAMP transduction pathway modify olfaction in Drosophila. J Comp Physiol A 2001, 187:359-370.

46. Gomez-Diaz C, Martin F. Alcorta E. The cAMP transduction cascade mediates olfactory reception in Drosophila melanogaster. Behav Genet 2004, 34:395-406.

47. Gomez-Diaz C, Martin F, Alcorta E: The inositol 1,4,5-triphosphate kinase1 gene affects olfactory reception in Drosophila melanogaster. Behav Genet 2006, 36:309-321.
48. Boto T, Gomez-Diaz C, Alcorta E: Expression analysis of the 3 G-protein subunits, Galpha, Gbeta, and Ggamma, in the olfactory receptor organs of adult Drosophila melanogaster. Chem Senses 2010, 35:183-193.

49. Morrison DK, Murakami MS, Cleghon V: Protein kinases and phosphatases in the Drosophila genome. J Cell Biol 2000, 150:F57-F62.

50. Larsson MC, Domingos Al, Jones WD, Chiappe ME, Amrein H, Vosshall LB: Or83b encodes a broadly expressed odorant receptor essential for Drosophila olfaction. Neuron 2004, 43:703-714.

51. Hallem EA, Carlson JR: Coding of odors by a receptor repertoire. Cell 2006, 125:143-160.

52. Ronderos DS, Smith DP: Diverse signaling mechanisms mediate volatile odorant detection in Drosophila. Fly (Austin) 2009, 3:290-297.

53. Park S-K, Shanbhag SR, Wang Q, Hasan G, Steinbrecht RA, Pikielny CW: Expression patterns of two putative odorant-binding proteins in the olfactory organs of Drosophila have different implications for their functions. Cell Tissue Res 2000, 300:181-192.

54. Ha TS, Smith DP: A pheromone receptor mediates 11-cis-vaccenyl acetate-induced responses in Drosophila. J Neurosci 2006, 26:8727-8733.

55. Lockhart DJ, Dong H, Byrne MC, Follettie MT, Gallo MV, Chee MS, Mittmann M, Wang C, Kobayashi M, Horton H, Brown EL: Expression monitoring by hybridization to high-density oligonucleotide arrays. Nat Biotechnol 1996, 14:1675-1680.

56. Liu WM, Mei R, Di X, Ryder TB, Hubbell E, Dee S, Webster TA, Harrington CA, Ho MH, Baid J, Smeekens SP: Analysis of high density expression microarrays with signed-rank call algorithms. Bioinformatics 2002, 18:1593-1599.

57. Wu Z, Irizarry RA: Preprocessing of oligonucleotide array data. Nat Biotechnol 2004, 22:656-658.

58. Benjamini $Y$, Hochberg $Y$ : Controlling the false discovery rate: a practical and powerful approach to multiple testing. J R Stat Soc B 1995, 57:289-300.

59. Ivanov D, Dvoriantchikova G, Pestova A, Nathanson L, Shestopalov VI: Microarray analysis of fiber cell maturation in the lens. FEBS Lett 2005 579:1213-1219.

60. Lian IA, Toft JH, Olsen GD, Langaas M, Bjørge L, Eide IP, Børdahl PE, Austgulen R: Matrix metalloproteinase 1 in pre-eclampsia and fetal growth restriction: reduced gene expression in decidual tissue and protein expression in extravillous trophoblasts. Placenta 2010 31:615-620.

61. Zheng D, Kille P, Feeney GP, Cunningham P, Handy RD, Hogstrand C: Dynamic transcriptomic profiles of zebrafish gills in response to zinc supplementation. BMC Genomics 2010, 11:553.

62. Livak KJ, Schmittgen TD: Analysis of relative gene expression data using real-time quantitative $P C R$ and the 2(-Delta Delta $C(T)$ ) Method. Methods 2001, 25:402-408

63. Helfand SL, Carlson JR: Isolation and characterization of an olfactory mutant in Drosophila with a chemically specific defect. Proc Natl Acad Sci U S A 1989, 86:2908-2912.

64. Devaud JM: Experimental studies of adult Drosophila chemosensory behaviour. Behav Processes 2003, 64:177-196.

doi:10.1186/1471-2164-14-259

Cite this article as: Riveron et al:: Transcriptional basis of the acclimation to high environmental temperature at the olfactory receptor organs of Drosophila melanogaster. BMC Genomics 2013 14:259.

\section{Submit your next manuscript to BioMed Central and take full advantage of:}

- Convenient online submission

- Thorough peer review

- No space constraints or color figure charges

- Immediate publication on acceptance

- Inclusion in PubMed, CAS, Scopus and Google Scholar

- Research which is freely available for redistribution 